CARDIOVASCULAR MEDICINE

\title{
Safety and cardiac chronotropic responsiveness to the early injection of atropine during dobutamine stress echocardiography in the elderly
}

\author{
J M Tsutsui, F Cerqueira Lario, D R Fernandes, I Kowatsch, J C Sbano, J A Franchini \\ Ramires, W Mathias Jr
}

See end of article for authors' affiliations

Correspondence to: Dr Jeane M Tsutsui, Heart Institute (InCor), University of Sao Paulo Medical School, Av Dr Enéas Carvalho de Aguiar, 44, Sao Paulo, Brazil, CEP 05403-000; jeanetsutsui@ msn.com

Accepted 15 March 2005 Published Online First 29 March 2005

\begin{abstract}
Objective: To determine the safety and cardiac chronotropic responsiveness to early atropine dobutamine stress echocardiography (DSE) in the elderly.

Design: Retrospective study of 258 patients $\geqslant 70$ years who underwent early atropine DSE and 290 patients $\geqslant 70$ years who underwent conventional DSE. In the early atropine protocol, atropine was started at $20 \mu \mathrm{g} / \mathrm{kg} / \mathrm{min}$ of dobutamine if heart rate was $<100$ beats $/ \mathrm{min}$, up to $2 \mathrm{mg}$. The cardiac chronotropic responsiveness in the elderly was compared with a control group of patients $<70$ years matched for sex, myocardial infarction, diabetes, and treatment with $\beta$ blockers and calcium channel blockers.

Results: The dose of dobutamine given to elderly patients was lower during early atropine than during conventional DSE (mean (SD) 29 (7) $\vee 38(4) \mu \mathrm{g} / \mathrm{kg} / \mathrm{min}, \mathrm{p}=0.001$ ). Early atropine DSE resulted in diminished incidence of ventricular extrasystoles, non-sustained ventricular tachycardia, bradycardia, and hypotension compared with conventional DSE. In comparison with patients $<70$ years, elderly patients required lower doses of dobutamine and atropine and achieved a higher percentage of predicted maximum heart rate $(92(9) \% \vee 88(10) \%, p=0.0001)$. Except for more common hypotension $(16 \% v$ $10 \%, p=0.004)$, no other difference in adverse effects was observed between patients $\geqslant 70$ and $<70$ years.

Conclusions: Early atropine DSE is a safe strategy in the elderly resulting in lower incidence of minor adverse effects than with the conventional protocol. Elderly patients presented adequate cardiac chronotropic responsiveness to early injections of atropine, requiring lower doses of drugs to reach test end points.
\end{abstract}

\begin{abstract}
C oronary artery disease (CAD) is highly prevalent and the leading cause of cardiac morbidity and mortality in dobutamine stress echocardiography (DSE) has become a widely used method for the non-invasive evaluation of CAD in this population. ${ }^{3-5}$ Recent modifications in the DSE protocols include earlier injection of atropine in patients with poor chronotropic response to dobutamine. ${ }^{67}$ This strategy has been shown to be safe and effective in reducing the test duration, maintaining similar diagnostic accuracy for detecting angiographically significant $C A D$ to that with the conventional protocol. ${ }^{8}$ No data exist, however, about the safety profile of this strategy in the elderly. Moreover, some concerns remain regarding the presence of a diminished adrenergic responsiveness with aging. Although the chronotropic response to bolus injections of isoproterenol in older animals and senescent humans was shown to be decreased, ${ }^{\text {,- }}$ ${ }^{11}$ no evidence for a reduced cardiac response to dobutamine was found in healthy elderly subjects. ${ }^{12}$ In this study, we sought to determine the safety and efficacy of the early injection of atropine during DSE in elderly patients with known or suspected CAD, as compared with the conventional protocol. In addition, we evaluated the differences in cardiac chronotropic responsiveness to early atropine DSE between patients $\geqslant 70$ and $<70$ years old.
\end{abstract}

\section{METHODS}

\section{Patients}

We retrospectively studied 290 patients $\geqslant 70$ years old (mean (SD) age 74 (3) years) who underwent conventional DSE from July 1991 to December 1999 and 258 patients $\geqslant 70$ years old (mean (SD) age 75 (4) years) who underwent early atropine DSE from January 2000 to June 2003. Patients were referred for DSE because of known or suspected CAD. The following exclusion criteria were observed: haemodynamic instability, unstable angina, recent myocardial infarction, submaximal tests performed for evaluation of myocardial viability, and contraindications to any drug used in the study. ${ }^{13}$ To evaluate the effect of aging on the adverse effects and chronotropic responsiveness to early atropine DSE, we also studied 258 patients $<70$ years old (mean (SD) age 58 (6) years) who underwent the same protocol, in the same period of time. Both groups $\geqslant 70$ and $<70$ years old were matched for sex, history of myocardial infarction, diabetes mellitus, and medication with $\beta$ blockers and calcium channel blockers. All patients in the early atropine DSE protocol received at least one dose of $0.25 \mathrm{mg}$ of atropine either at 20 or $30 \mu \mathrm{g} / \mathrm{kg} / \mathrm{min}$ of dobutamine. Table 1 describes the clinical characteristics of patients in the conventional and early atropine DSE groups. The prevalence of risk factors for CAD did not differ between patients $\geqslant 70$ and $<70$ years old in the early atropine DSE groups, except for cigarette smoking.

\section{Dobutamine stress protocol}

During conventional DSE, intravenous dobutamine was infused at a starting dose of $5 \mu \mathrm{g} / \mathrm{kg} / \mathrm{min}$ followed by

Abbreviations: $C A D$, coronary artery disease; DSE, dobutamine stress echocardiography; PMHR, predicted maximum heart rate 
Table 1 Characteristics of patients undergoing dobutamine stress echocardiography (DSE)

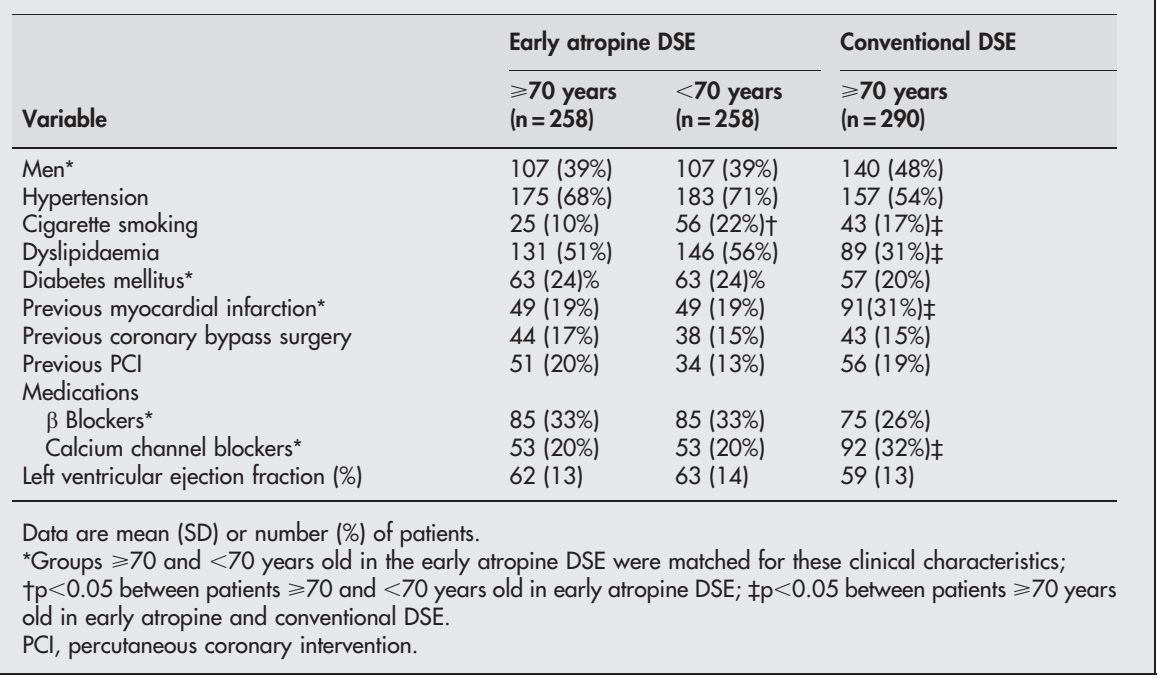

increasing doses of 10,20,30, and up to a maximum of $40 \mu \mathrm{g} /$ $\mathrm{kg} / \mathrm{min}$ in three minutes stages. ${ }^{13}$ In patients without signs of myocardial ischaemia who did not achieve $85 \%$ of predicted maximum heart rate (PMHR) (220 in men, and 200 in women) with the maximum dose of dobutamine, atropine was administered in doses of $0.25 \mathrm{mg}$ each minute, up to a maximum of $1.0 \mathrm{mg}$. During early atropine DSE, dobutamine was infused in a similar way, but atropine was started at the beginning of the $20 \mu \mathrm{g} / \mathrm{kg} / \mathrm{min}$ of dobutamine stage if the heart rate was $<100$ beats $/ \mathrm{min}$, in doses of $0.25 \mathrm{mg}$ each minute, up to $2 \mathrm{mg} .{ }^{8}$ When a heart rate $\geqslant 100$ beats/min had already been achieved at the beginning of the $20 \mu \mathrm{g} / \mathrm{kg} / \mathrm{min}$ stage, atropine was injected with $30 \mu \mathrm{g} / \mathrm{kg} / \mathrm{min}$ of dobutamine. Blood pressure, heart rate, and 12 lead ECG were monitored at each stage of dobutamine infusion. End points of the tests were achievement of target heart rate, ${ }^{42}$ maximum dobutamine and atropine doses, development of severe or extensive wall motion abnormalities, ST elevation $>0.1 \mathrm{mV}$ at an interval of $80 \mathrm{~ms}$ after the $\mathrm{J}$ point in patients without a previous myocardial infarction, sustained arrhythmias, severe angina, or intolerable side effects. ${ }^{13}$ Metoprolol (5-15 mg) was injected intravenously to reverse the effects of dobutamine if they did not revert quickly after test termination.

\section{Image acquisition and analysis}

Images were acquired at rest, low dose of dobutamine, peak stress, and recovery phases and displayed side by side in a quad screen format. All images were recorded on videotape and digitised in continuous loop format for later analysis. Left ventricular ejection fraction was estimated at rest by two dimensional echocardiography with the modified Simpson's rule. The stress tests were considered positive for myocardial ischaemia if they showed new or worsening of pre-existing wall motion abnormalities in $\geqslant 2$ contiguous segments. ${ }^{13}$ The tests were considered diagnostic either if they were positive for ischaemia or achieved the target heart rate, and nondiagnostic when they were prematurely interrupted because of significant adverse effect or did not achieve the target heart rate despite maximum doses of dobutamine and atropine.

\section{Safety}

Hypertension was defined as blood pressure $>230$ / $120 \mathrm{~mm} \mathrm{Hg}$. Hypotension was defined as systolic blood pressure $<100 \mathrm{~mm} \mathrm{Hg}$ or a drop $>20 \mathrm{~mm} \mathrm{Hg}$ from baseline. ${ }^{4}{ }^{14}$ Symptomatic hypotension was defined as hypotension associated with significant symptoms causing test termination. Major adverse effects were defined as those that would potentially cause a life threatening situation or that led to new hospital admission. ${ }^{15}$

\section{Statistical analysis}

Continuous variables were expressed as mean (SD) and categorical variables as proportions. Two tailed unpaired and paired Student's $t$ tests were used for intergroup and intragroup comparisons, respectively. Fisher's exact and $\chi^{2}$ tests were used for comparison of proportions. All data were analysed by SPSS statistical package (SPSS 11.0 for Windows; SPSS Inc, Chicago, Illinois, USA). A probability value of $p<0.05$ was considered significant.

\section{RESULTS}

\section{Safety and efficacy of early atropine versus} conventional DSE in the elderly

The mean maximum dose of dobutamine used during early atropine DSE was lower than during the conventional protocol $(29$ (7) $v 38(4) \mu \mathrm{g} / \mathrm{kg} / \mathrm{min}, \mathrm{p}=0.001)$. Only $21 \%$ of patients required the $40 \mu \mathrm{g} / \mathrm{kg} / \mathrm{min}$ stage to achieve the stress end points. During conventional DSE $85 \%$ of patients received this high dose of dobutamine (table 2). The test duration was significantly shorter during early atropine than during conventional DSE (12 (2) min $v \quad 15$ (2) min, $\mathrm{p}<0.001)$. Patients reached similar rates of PMHR at peak stress in both protocols (92\% (9\%) v 91\% (14\%), $\mathrm{p}=0.98)$. The test was diagnostic in $243(94 \%)$ patients undergoing early atropine DSE and in $260(89 \%)$ of patients undergoing conventional DSE ( $p=0.06$ between groups). Table 3 describes the adverse effects observed in elderly patients who underwent early atropine and conventional DSE. The incidence of ventricular extrasystoles, non-sustained ventricular tachycardia, bradycardia, and hypotension were significantly lower in the early atropine than in the conventional DSE groups. Arrhythmias were terminated spontaneously or after administration of metoprolol. Symptomatic hypotension leading to test termination was more common in conventional than in early atropine DSE. On the other hand, hypertension was observed more often in the early atropine protocol. No myocardial infarction, death, sustained ventricular tachycardia, or ventricular fibrillation occurred in either group during or immediately after dobutamine stress tests. 
Table 2 Drugs used in DSE with early injection of atropine

\begin{tabular}{|c|c|c|c|}
\hline \multirow[b]{2}{*}{ Drug } & \multicolumn{2}{|c|}{ Early atropine DSE } & \multirow{2}{*}{$\begin{array}{l}\text { Conventional DSE } \\
\geqslant 70 \text { years }(n=290 \text { ) }\end{array}$} \\
\hline & $\begin{array}{l}\geqslant 70 \text { years } \\
(n=258)\end{array}$ & $\begin{array}{l}<70 \text { years } \\
(n=258)\end{array}$ & \\
\hline Total dobutamine dose $(\mu \mathrm{g} / \mathrm{kg} / \mathrm{min})$ & $29(7)$ & $31(6)^{*}$ & $38(4) \dagger$ \\
\hline Total atropine dose $(\mathrm{mg})$ & $0.6(0.5)$ & $0.8(0.5)^{*}$ & $0.4(0.2) \dagger$ \\
\hline \multicolumn{4}{|c|}{ Atropine dose $(\mathrm{mg})$ at each stage of dobutamine $(\mu \mathrm{g} / \mathrm{kg} / \mathrm{min})$} \\
\hline 20 & $0.3(0.2)$ & $0.4(0.2)$ & \\
\hline 30 & $0.4(0.3)$ & $0.5(0.3)$ & \\
\hline 40 & $0.5(0.3)$ & $0.6(0.4)^{*}$ & $0.4(0.2)$ \\
\hline Atropine started at $20 \mu \mathrm{g} / \mathrm{kg} / \mathrm{min}$ of dobutamine & $226(87 \%)$ & $223(86 \%)$ & \\
\hline Atropine started at $30 \mu \mathrm{g} / \mathrm{kg} / \mathrm{min}$ of dobutamine & $32(13 \%)$ & $35(14 \%)$ & \\
\hline $\begin{array}{l}\text { Stage of } 40 \mu \mathrm{g} / \mathrm{kg} / \mathrm{min} \text { of dobutamine needed to } \\
\text { achieve test end points }\end{array}$ & $55(21 \%)$ & $69(27 \%)^{*}$ & $247(85 \%) \dagger$ \\
\hline \multicolumn{4}{|c|}{$\begin{array}{l}\text { Data are mean (SD) or number (\%) of patients. } \\
{ }^{*} p<0.05 \text { between patients } \geqslant 70 \text { and }<70 \text { years old in early atropine DSE; } \uparrow p<0.05 \text { between patients } \geqslant 70 \text { year } \\
\text { in early atropine and conventional DSE. }\end{array}$} \\
\hline
\end{tabular}

Early atropine DSE in patients $\geqslant \mathbf{7 0}$ and $<\mathbf{7 0}$ years old The doses of dobutamine (29 (7) $v 31$ (6) $\mu \mathrm{g} / \mathrm{kg} / \mathrm{min}$,

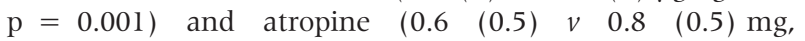
$\mathrm{p}=0.001)$ required to achieve test end points were lower in patients $\geqslant 70$ than in patients $<70$ years old who underwent early atropine DSE. However, when considering each stage of dobutamine separately, no difference was observed in the dose of atropine used between both groups (table 2). The percentage of diagnostic tests was similar between patients $\geqslant 70$ and $<70$ years old $(94 \% \vee 90 \%$, $\mathrm{p}=0.07)$. Although patients had a similar prevalence of hypertension and other clinical variables, blood pressure at baseline was higher in older than in younger patients. At peak stress, systolic blood pressure levels were maintained in patients $\geqslant 70$ years old $(\mathrm{p}=0.15)$ and diastolic blood pressure decreased significantly relative to baseline $(\mathrm{p}<0.001)$. On the other hand, in younger patients systolic blood pressure increased significantly at peak stress $(\mathrm{p}<0.001)$. Although the rate-pressure product was similar between groups at baseline, at peak stress patients $<70$ years old reached a significantly higher rate-pressure product than did patients $\geqslant 70$ years old (table 4 ). Arrhythmias, chest pain, or hypertension did not differ between the groups. However, hypotension was more often observed in older patients (table 4).

\section{Cardiac chronotropic responsiveness to early atropine DSE}

The analysis of chronotropic responsiveness at each stage of dobutamine infusion showed that the heart rate was similar between older and younger patients at baseline (69 (12) $v 69$ (12) beats $/ \mathrm{min}, \mathrm{p}=1.0)$, at $10 \mu \mathrm{g} / \mathrm{kg} / \mathrm{min}$ of dobutamine (78 (15) $v 78$ (17) beats $/ \mathrm{min}, \mathrm{p}=0.98$ ), and at $20 \mu \mathrm{g} / \mathrm{kg} / \mathrm{min}$ of dobutamine (107 (26) v 107 (27) beats/min, p = 0.81) (fig 1). At the end of the $20 \mu \mathrm{g} / \mathrm{kg} / \mathrm{min}$ stage of dobutamine infusion, a higher proportion of patients $\geqslant 70$ years old had already reached the target heart rate than had patients $<70$ years old $(21 \% v 13 \%$ of younger patients, $\mathrm{p}<0.001)$. The heart rate at the end of $30 \mu \mathrm{g} / \mathrm{kg} / \mathrm{min}$ of dobutamine was lower in patients $\geqslant 70$ years old ( $126(20)$ beats/min) than in patients $<70$ years old (136 (21) beats/min, p $<0.001)$. However, the percentage PMHR was significantly higher in older patients (fig 2). In a similar way, at $40 \mu \mathrm{g} / \mathrm{kg} / \mathrm{min}$ of dobutamine the heart rate was lower (125 (14) $v 138$ (18) beats/min, $p=0.001$ ) but the percentage PMHR was higher $(95 \% \vee 91 \%, \mathrm{p}=0.01)$ in patients $\geqslant 70$ than in patients $<70$ years old.

\section{DISCUSSION}

As a result of prolonged mean life expectancy and improvements in treatment approaches, non-invasive evaluation of CAD has increasingly been required in elderly patients. DSE has proved to be an accurate method for detecting CAD and predicting cardiac events in this patient population. ${ }^{45}{ }^{14}$ Although the injection of atropine in early stages of dobutamine has been recently incorporated into DSE protocols, ${ }^{16}$ no data exist regarding the appropriateness of this strategy in the elderly. In the present study we assessed the safety profile of the early injection of atropine during DSE in 258 patients $\geqslant 70$ years old with known or suspected CAD.

Table 3 Adverse effects

\begin{tabular}{|c|c|c|c|}
\hline \multirow[b]{2}{*}{ Adverse effect } & \multicolumn{2}{|c|}{ Early atropine DSE } & \multirow{2}{*}{$\begin{array}{l}\text { Conventional DSE } \\
\geqslant 70 \text { years }(n=290 \text { ) }\end{array}$} \\
\hline & $\begin{array}{l}\geqslant 70 \text { years } \\
(n=258)\end{array}$ & $\begin{array}{l}<70 \text { years } \\
(n=258)\end{array}$ & \\
\hline \multicolumn{4}{|l|}{ Cardiac arrhythmias } \\
\hline Ventricular extrasystoles & $67(25.9 \%)$ & $60(23.2 \%)$ & $105(36.2 \%) \dagger$ \\
\hline Supraventricular extrasystoles & $35(13.6 \%)$ & $25(9.7 \%)$ & $42(14.5 \%)$ \\
\hline Non-sustained VT & $4(1.6 \%)$ & $1(0.4 \%)$ & $15(5.2 \%) \dagger$ \\
\hline Atrial fibrillation & $5(1.9 \%)$ & $3(1.2 \%)$ & $4(1.3 \%)$ \\
\hline Symptomatic bradycardia & 0 & $2(0.7 \%)$ & $6(2.1 \%) \dagger$ \\
\hline Chest pain & $26(10.1 \%)$ & $23(8.9 \%)$ & $38(13.1 \%)$ \\
\hline Nausea & $1(0.4 \%)$ & $4(1.5 \%)$ & $7(2.4 \%)$ \\
\hline Hypotension & $42(16.2 \%)$ & $23(9.6 \%)^{*}$ & $66(22.3 \%) \dagger$ \\
\hline Symptomatic hypotension & $3(1.2 \%)$ & $5(1.9 \%)$ & $11(3.7 \%) \dagger$ \\
\hline Hypertension & $9(3.5 \%)$ & $10(3.9 \%)$ & $2(0.7 \%) \dagger$ \\
\hline
\end{tabular}

Data are number (\%) of patients.

${ }^{*} \mathrm{p}<0.05$ between patients $\geqslant 70$ and $<70$ years old in early atropine DSE; $\uparrow \mathrm{p}<0.05$ between patients $\geqslant 70$ years in early atropine and conventional DSE.

$\mathrm{VT}$, ventricular tachycardia. 
Table 4 Haemodynamic data

\begin{tabular}{|c|c|c|c|}
\hline & \multicolumn{2}{|c|}{ Early atropine DSE } & \multirow{2}{*}{$\begin{array}{l}\text { Conventional DSE } \\
\begin{array}{l}\geqslant 70 \text { years } \\
(\mathrm{n}=290)\end{array}\end{array}$} \\
\hline & $\begin{array}{l}\geqslant 70 \text { years } \\
(\mathrm{n}=258)\end{array}$ & $\begin{array}{l}<70 \text { years } \\
(n=258)\end{array}$ & \\
\hline \multicolumn{4}{|l|}{ Baseline } \\
\hline Heart rate (beats/min) & $69(12)$ & $69(12)$ & $69(11)$ \\
\hline Systolic blood pressure (mm Hg) & $140(22)$ & $136(20)^{*}$ & $138(17)$ \\
\hline Diastolic blood pressure (mm Hg) & $81(10)$ & $84(10)^{*}$ & $80(11)$ \\
\hline Rate-pressure product $(\mathrm{mm} \mathrm{Hg} / \mathrm{min})$ & 9662 (2 148) & $9379(2311)$ & 9431 (2 521) \\
\hline \multicolumn{4}{|l|}{ Peak } \\
\hline Heart rate (beats/min) & $133(15)$ & $142(18)^{*}$ & $129(17) \dagger$ \\
\hline$\%$ Predicted maximum heart rate & $92(9)$ & $88(10)^{*}$ & $91(14)$ \\
\hline Systolic blood pressure $(\mathrm{mm} \mathrm{Hg})$ & $143(29)$ & $143(29)$ & $144(30)$ \\
\hline Diastolic blood pressure $(\mathrm{mm} \mathrm{Hg})$ & $72(16)$ & $78(17)^{*}$ & $64(17)$ \\
\hline Rate-pressure product (mm $\mathrm{Hg} / \mathrm{min})$ & 19033 (4 282) & $20324(4642)^{*}$ & 18989 (4 284) \\
\hline \multicolumn{4}{|c|}{$\begin{array}{l}\text { Data are mean (SD). } \\
\text { " } p<0.05 \text { between patients } \geqslant 70 \text { and }<70 \text { years old in early atropine } D S E ; ~ \\
\text { in early atropine and conventional } D S E \text {. }\end{array}$} \\
\hline
\end{tabular}

Additionally, the differences in chronotropic responsiveness to early atropine DSE were assessed in patients $\geqslant 70$ and $<70$ years old matched for sex and other clinical characteristics known to influence the chronotropic response to dobutamine. $^{41718}$ Although early injection of atropine has been recently proposed for DSE, no standardised recommendations exist. The report of the British Society of Echocardiography ${ }^{16}$ recommends that atropine should be considered when heart rate has not increased after admin-

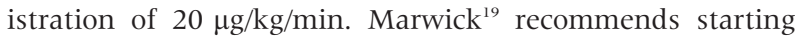
atropine when heart rate has not increased by $>10 \%$ or remains at $<70$ beats $/ \mathrm{min}$ at the stage of $20 \mu \mathrm{g} / \mathrm{kg} / \mathrm{min}$, since these patients will almost certainly need atropine. In the present study, we followed the same protocol being used in our institution since January $2000 .{ }^{8}$ We showed that early atropine DSE resulted in a lower incidence of minor side effects than with conventional DSE. Although the efficacy of the test was the same, this reduction in minor adverse effects may favour the use of early atropine DSE in the elderly. Previous studies have shown an increased incidence of exercise induced ${ }^{20}$ and dobutamine induced arrhythmias with aging. Hiro et $a l^{4}$ reported a higher incidence of ventricular arrhythmias during conventional DSE in patients $\geqslant 75$ years old. Elhendy et $a l^{14}$ reported that patients $\geqslant 70$ years old had a higher incidence of supraventricular arrhythmias and ventricular extrasystoles during myocardial perfusion scintigraphy according to the conventional protocol of dobutamine stress. In our study, early atropine resulted in a lower incidence of arrhythmias than did conventional DSE, but no differences were observed between older and younger

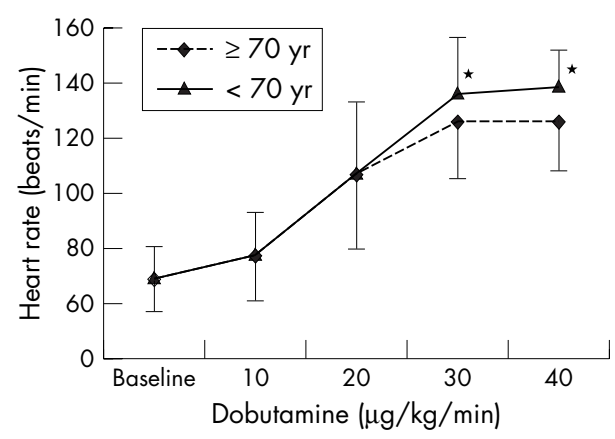

Figure 1 Heart rate at each stage of dobutamine in patients $\geqslant 70$ years old and $<70$ years old who underwent early injection of atropine during dobutamine stress echocardiography. Note that the heart rate achieved at 30 and $40 \mu \mathrm{g} / \mathrm{kg} / \mathrm{min}$ of dobutamine was lower in patients $\geqslant 70$ years old. * $\mathrm{p}<0.05$ between groups. patients who underwent early atropine DSE. By starting atropine in the early stages of dobutamine infusion, the maximum dose of dobutamine required to achieve test end points was significantly lower than in the conventional protocol. The diminished exposure of patients to high doses of an adrenergic stimulant drug probably accounted for these findings.

Elderly patients had a lower incidence of hypotension during early atropine DSE than during conventional DSE but more patients $\geqslant 70$ than $<70$ years old experienced this adverse effect. Although patients had a similar prevalence of hypertension and treatment with $\beta$ blockers and calcium channel blockers, a different haemodynamic profile during early atropine DSE was observed between patients $\geqslant 70$ and $<70$ years old. The higher rates of dobutamine stress induced hypotension in the elderly had already been described by other investigators. ${ }^{14}{ }^{17}$ In our study, younger patients had lower levels of resting systolic blood pressure, which increased at peak stress. On the other hand, more of the patients $\geqslant 70$ years old had episodes of hypotension during stress. Limiting hypotension was more often observed in elderly patients who underwent conventional DSE (3.7\%) than in patients who underwent early atropine DSE (1.2\%). The possible mechanisms underlying this phenomenon include diminished baroreflex sensitivity and abnormal blood pressure homeostasis in the elderly, ${ }^{21}$ resulting in higher susceptibility of these patients to the peripheral vasodilatation that occurs by dobutamine stimulation of $\beta_{2}$ receptors. Furthermore, it has already been established that stress induced hypotension is not related to the degree of CAD. ${ }^{17}{ }^{22}$

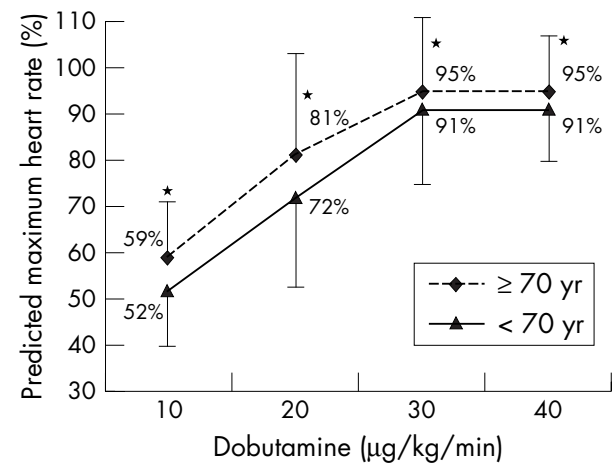

Figure 2 Percentage of predicted maximum heart rate reached at each stage of dobutamine in patients $\geqslant 70$ years old and $<70$ years old who underwent early injection of atropine during dobutamine stress echocardiography. ${ }^{*} \mathrm{p}<0.05$ between groups. 
No major complications from the stress test were observed in any group, confirming previous reports in the literature. ${ }^{15} 2324$

\section{Chronotropic responsiveness to dobutamine and atropine}

Atropine is a muscarinic cholinergic antagonist with parasympatholytic and vagolytic activity. ${ }^{25}$ The possible effects of early atropine injection during DSE on chronotropic responses in the elderly had not been tested before. The ability of DSE to detect myocardial ischaemia depends on an adequate increase in myocardial oxygen consumption, which is directly related to the heart rate achieved at peak stress. Previous animal studies have raised concerns regarding a diminished $\beta$ adrenoceptor mediated responsiveness to bolus injections of isoproterenol in older rats. ${ }^{10}$ A reduced chronotropic response to isoproterenol was also reported in elderly subjects with low risk for CAD. ${ }^{11}$ Elderly patients with diabetes, hypertension, smoking, and previous myocardial infarction were shown to have a decreased sensitivity to dobutamine, but no evidence for reduced $\beta$ adrenoceptor responsiveness to dobutamine was found in healthy elderly subjects who underwent DSE. ${ }^{12}$ Our study population had some clinical characteristics associated with diminished sensitivity to dobutamine and included a significant number of patients taking $\beta$ blockers. However, a high percentage of patients achieved the target heart rate, probably due to the lower calculated PMHR for older patients, resulting in achievement of the target rate heart with lower doses of drugs. By performing a stepwise analysis of heart rate at each stage of dobutamine, we showed that older patients achieved a lower heart rate during stress than younger patients. However, the PMHR reached at peak stress was higher, and test end points were achieved with lower doses of dobutamine and atropine.

\section{Conclusions}

Our study showed that early injection of atropine during DSE is a safe strategy in patients $\geqslant 70$ years old with known or suspected CAD. Cardiac chronotropic responsiveness to early atropine DSE is adequate in elderly patients, requiring lower doses of drugs to achieve test end points.

\section{Authors' affiliations \\ J M Tsutsui, F Cerqueira Lario, D R Fernandes, I Kowatsch, J C Sbano, J A Franchini Ramires, W MathiasJr, Echocardiography Laboratory, Heart Institute (InCor), University of São Paulo Medical School, Sao Paulo, Brazil \\ Ethics approval: The study was approved by ethical committee of the Heart Institute (InCor) and written consent form was obtained from all participants. \\ REFERENCES \\ 1 Chaitman BR, Bourassa MG, Davis K, et al. Angiographic prevalence of high- risk coronary artery disease in patient subsets (CASS). Circulation $1981 ; 64: 360-7$. \\ 2 Coodley EL. Clinical spectrum and diagnostic techniques of coronary heart disease in the elderly. J Am Geriatr Soc 1988;36:447-56.}

3 Poldermans D, Fioretti PM, Boersma E, et al. Dobutamine-atropine stress echocardiography in elderly patients unable to perform an exercise test: hemodynamic characteristics, safety, and prognostic value. Arch Intern Med 1994; 154:2681-6.

4 Hiro J, Hiro T, Reid CL, et al. Safety and results of dobutamine stress echocardiography in women versus men and in patients older and younger than 75 years of age. Am J Cardiol 1997;80:1014-20.

5 Anthopoulos LP, Bonou MS, Kardaras FG, et al. Stress echocardiography in elderly patients with coronary artery disease: applicability, safety and prognostic value of dobutamine and adenosine echocardiography in elderly patients. J Am Coll Cardiol 1996;28:52-9.

6 Lewandowski TJ, Armstrong WF, Bach DS. Reduced test time by early identification of patients requiring atropine during dobutamine stress echocardiography. J Am Soc Echocardiogr 1998;11:236-42.

7 Lessick J, Mutlak D, Rinkevich D, et al. Prospective study of early atropine use in dobutamine stress echocardiography. Eur J Echocardiogr 2000;1:257-62.

8 Tsutsui JM, Osorio AF, Lario FA, et al. Comparison of safety and efficacy of the early injection of atropine during dobutamine stress echocardiography with the conventional protocol. Am J Cardiol 2004:94:1367-72.

9 Kendall MJ, Woods KL, Wilkins MR, et al. Responsiveness to beta-adrenergic receptor stimulation: the effects of age are cardioselective. Br J Clin Pharmacol 1982;14:821-6.

10 Vestal RE, Wood AJ, Shand DG. Reduced beta-adrenoceptor sensitivity in the elderly. Clin Pharmacol Ther 1979;26:181-6.

11 Van Brummelen P, Buhler FR, Kiowski W, et al. Age-related decrease in cardiac and peripheral vascular responsiveness to isoprenaline: studies in normal subjects. Clin Sci (Lond) 1981;60:571-7.

12 Poldermans D, Boersma E, Fioretti PM, et al. Cardiac chronotropic responsiveness to beta-adrenoceptor stimulation is not reduced in the elderly. J Am Coll Cardiol 1995;25:995-9.

13 Armstrong WF, Pellikka PA, Ryan T, et al. Stress echocardiography: recommendations for performance and interpretation of stress echocardiography. Stress Echocardiography Task Force of the Nomenclature and Standards Committee of the American Society of Echocardiography. J Am Soc Echocardiogr 1998;11:97-104.

14 Elhendy A, van Domburg RT, Bax JJ, et al. Safety, hemodynamic profile, and feasibility of dobutamine stress technetium myocardial perfusion single-photon emission CT imaging for evaluation of coronary artery disease in the elderly. Chest 2000;117:649-56.

15 Picano E, Mathias W Jr, Pingitore A, et al. Safety and tolerability of dobutamine-atropine stress echocardiography: a prospective, multicentre study. Echo Dobutamine International Cooperative Study Group. Lancet 1994;344: 1190-2.

16 Becher H, Chambers J, Fox K, et al. BSE procedure guidelines for the clinical application of stress echocardiography, recommendations for performance and interpretation of stress echocardiography: a report of the British Society of Echocardiography Policy Committee. Heart 2004;90(suppl 6):vi23-30.

17 Marcovitz PA, Bach DS, Mathias W, et al. Paradoxic hypotension during dobutamine stress echocardiography: clinical and diagnostic implications. J Am Coll Cardiol 1993;21:1080-6.

18 Fioretti PM, Poldermans D, Salustri A, et al. Atropine increases the accuracy of dobutamine stress echocardiography in patients taking beta-blockers. Eur Heart J 1994; 15:355-60.

19 Marwick T. Performance of stress echocardiography. In: Marwick T, eds. Stress echocardiography. Its role in the diagnosis and evaluation of coronary artery disease, 2nd ed. Dordrecht: Kluwer Academic Publishers Group, 2003: 1-42.

20 Mayuga R, Arrington CT, O'Connor FC, et al. Why do exercise-induced ventricular arrhythmias increase with age? Role of $M$-mode echocardiographic aging changes. J Gerontol A Biol Sci Med Sci 1996;51:M23-8.

21 Lipsitz LA. Abnormalities in blood pressure homeostasis that contribute to falls in the elderly. Clin Geriatr Med 1985;1:637-48.

22 Rosamond TL, Vacek JL, Hurwitz A, et al. Hypotension during dobutamine stress echocardiography: initial description and clinical relevance. Am Heart $J$ 1992;123:403-7.

23 Mathias W Jr, Arruda A, Santos FC, et al. Safety of dobutamine-atropine stress echocardiography: a prospective experience of 4,033 consecutive studies. J Am Soc Echocardiogr 1999;12:785-91.

24 Secknus MA, Marwick TH. Evolution of dobutamine echocardiography protocols and indications: safety and side effects in 3,011 studies over 5 years. J Am Coll Cardiol 1997;29:1234-40.

25 Brown JH, Taylor P. Muscarinic receptor agonists and antagonists. In: Hardman JG, Limbird LE, eds. Goodman and Gilman's the pharmacologic basis of therapeutics. New York: McGraw-Hill, 2001:167-73. 